\title{
Research on the New Pattern and Applications of Incentive Control Mechanism on Enterprise Human Resource Management
}

\author{
Xiaomei $\mathrm{Su}^{1}$ \\ ${ }^{1}$ Langfang Teachers University, \\ Langfang,Hebei, 065000 China
}

\begin{abstract}
In this paper, we conduct research on the new pattern and applications of incentive control mechanism on enterprise human resource management. Enterprise's development cannot leave the support of talents, the key link to attract and retain talent is to do a good job in human resources management of human resource management is one of the important factors of enterprise survival and development has the vital significance to the enterprise, based on this, this article is to the enterprise human resources management and incentive management focus to explore, analyze its characteristics and existing problems, and actively looking for a solution to the problem, in order to promote the development of enterprises better which will be meaningful for companies and institutions.
\end{abstract}

Keywords: Incentive Control; Human Resource Management; New Pattern; Operation Mechanism.

\section{Introduction}

With the rapid development of social production and the degree of further integration of marketization of enterprises, enterprises have no boundary into the economic system and the global business environment. Workers are the main factors of production, economic activity is the main resource for spiritual and material wealth creation, in the new competition environment and the challenges, the development and management of human resources will be related to the survival and development of the company. New economy under the background of human resource management is a very important problem, we also need in the process of human resources management combined with its own characteristics in order to optimize the general quality of human resource management, therefore, in the following we will for the new economy under the background of a detailed analysis of the characteristics of human resources management. With knowledge for dominance in the new economic environment, the uniqueness of the human resource and knowledge capital advantage become important core skills, the value of human resources as the symbol of the measure of enterprise overall competitiveness and the human resource management under the new economy in the new era reflects the basic requirements of the rules of the game at the same time, more has the deep imprint of industrial civilization era, make it present a new features. Macro human resource management refers to a country or a region of the human resource management, namely human resource management of the whole society. Mainly focus on the overall of the formation, development and utilization of human resources management. Countries through the establishment of a series of system, government policy, take some necessary measures to promote the formation of human resources. Provide the conditions for the formation and development and utilization of human resources.

Incentive theory is the attempt to explain and predict a person in the organization behavior and for the organization to ensure the consistency between employee behavior and organizational goals. The theory could be summarized as the follows. (1) The process type incentive theory. 
Strengthening theory holds that strengthening people's behavior to strengthen order affects people tend to repeat the behavior, so most of the people by strengthening the environment will be more hard work. The expectations of the theory are that motivation depends on the result of the behavior and the behavior caused by the expectations of satisfaction, so the theory is focused on the future. Goal setting theory is that people's values and goals tend to affect their performance, values that people get they think something of value. (2) The content type incentive theory. Content type incentive theory mainly studies the causes of human behavior, that is, what kind of specific stimulation factors will motivate people. McClelland achievement motivation theory is that people are asked to work according to the high standards or the desire to win competition motivation. He thinks, although almost everyone felt achievement motivation, but only very few people are motivated by the desire for achievement. The main reason is that early professional experience, experience, and the type of organization determines the strength of the incentive. Moreover, the influence of financial incentives for high achievers is not a single [1]. In the process of achievement motivation works, excellent work performance may be attractive to people, but if high achievers in boring or routine work, or is the job of the general lack of competitive, so lost the achievement motivation.

In recent years, the human resources as a kind of important resources more and more becomes the enterprise value. Incentive as development and management of human resources is an important method has been used more and more enterprises, it is the demand for people desire meet or limit of appropriately, and the essence of which is willing to level of the people in the pursuit of a goal. Human resources management is also a part of one of the most difficult coordination in the process of enterprise management. It will basically corresponds to the human resources management process and enterprise development strategy, formulate strategic human resources management mode, and develop people, make the enterprise regards human resources optimal configuration which will improve the enterprise management mode, realize the goal of enterprise management so as to make the enterprise stable and sustainable development to be able to realize the ultimate strategic goal.

In this paper, we theoretically research on the new pattern and applications of incentive control mechanism on enterprise human resource management [2]. Corresponds to the primary human resource management and enterprise strategy can guarantee the implementation of the strategy of enterprise, has the important status of the widely recognized in particular. Strategy refers to the enterprises can very clearly determine the key success factors and competitive strategy, and through the management of human resource management, especially the five insurance practice and make the organization members to the enterprise's strategic goal and direction more clearly. In the following discussions, we will research the mentioned issues in detail with theoretical analysis.

\section{Our Proposed Methodology}

The Incentive Control Mechanism. Incentive mechanism in management activities, according to the personal psychological change, is used to stimulate personal potential power, promote the individual to pursue an organic management has set goals. Is also for this reason, the stand or fall of incentive mechanism in human resource management, is directly related to whether an enterprise worker, condensed the worker can be united which will affect the healthy and stable development of the enterprise. Enterprise management to the employees' motivation could be summarized as the following sub-parts. (1) Attaches great importance to the emotional incentive. In the modern and rapid developing enterprise management, the emotional incentive 
is a very valuable and rich, need to attach great importance to and need to strengthen the development of incentive mode. Trust takes care of people, make the staff feel the warmth of the collective, employees will have more effective driving force for the enterprise, and mobilize their collective sense of honor, foster a sense of ownership. (2) Establish and improve the appropriate incentive mechanism. Motivation is not completely rewards, including constraints and punishment. Establish and improve the moderate elimination mechanism can make the enterprise more energetic which can give full play to the subjective initiative of employees. (3) To employees demand as the starting point to establish incentive mechanism. To make a effective incentive to must correctly understand and analyze the needs of each relevant personnel. For employees, professional development is a great life. If the enterprise on the career development, to give employees enough help and guidance, make its own ideal, so employees will do their best, for the enterprise to return enterprise with loyalty and performance. (3) Establishing the general incentive mechanism for enterprises. Incentive is a mechanism that originally belonging to the category of management. The development of human resources need external condition is satisfied, but also cannot kill human resources internal factors on the role of human resource development. (4) Encourage the mechanism of resource sharing. Resource sharing and participate in the management can fully arouse the enthusiasm of employees, improve staff knowledge, timely popularization of information technology, will also increase employee's expectations of the enterprise status [3]. It must be greatly open enterprise information, to make employees feel really is the owner of the enterprise. In the figure one, we illustrate the flowchart of incentive control human resources management.

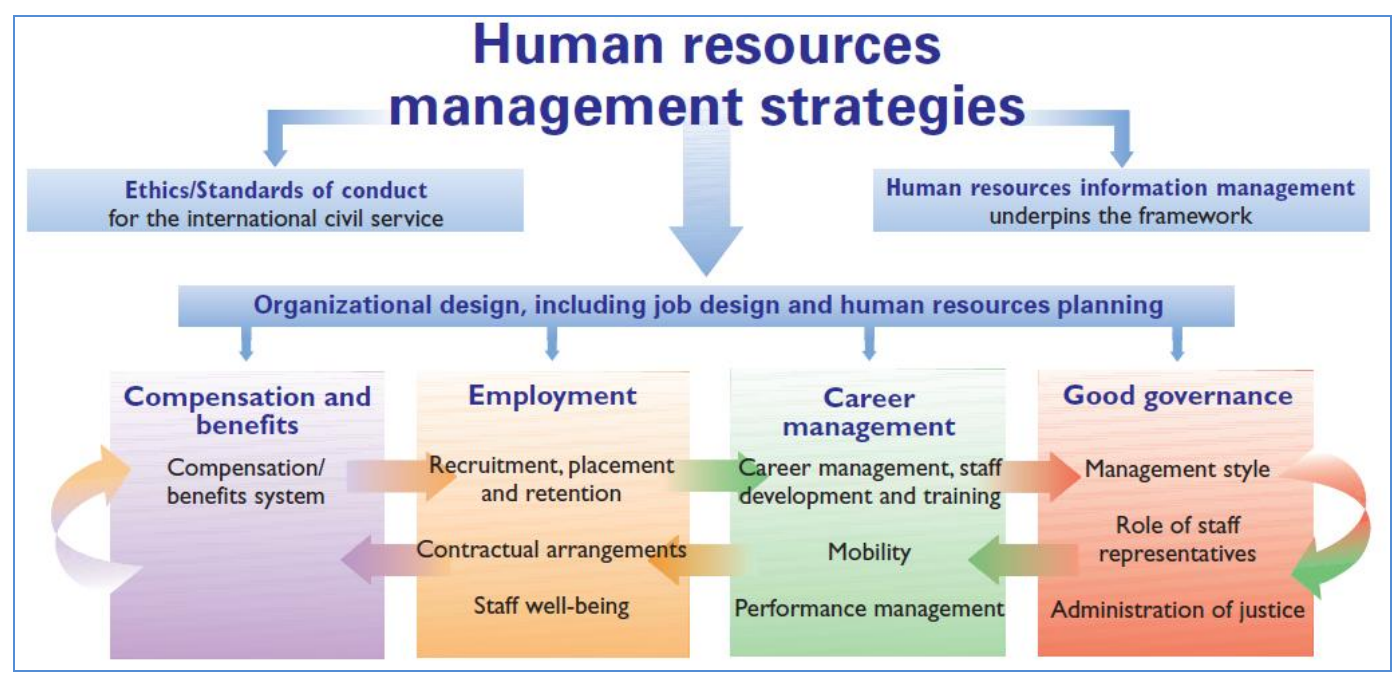

Figure 1. The Flowchart of Incentive Control Human Resources Management

The Enterprise Human Resource Management. After entering the knowledge economy era, enterprises urgently need to be highly qualified talent resources of our country. But enterprises since the start produce due to the deficiency of various historical reasons lead to the enterprise itself, and in its development due to the low level of development and the management pattern, the backward concept of talent, imperfect compensation system, lack of communication and the exchange, ignore the employee's learning, training and talent development of their business and career planning, and make the development of enterprises such as head of the enterprise concept trapped in its own defects "talent". Is in urgent 
need of qualified personnel on one hand, on the other hand after get the high quality talent is hard to with the effective human resource management in a relatively short time to retain talent, and reach their maximum potential. Human resource is the foundation of enterprise survival and development conditions. Bottom is the talented person's competition, therefore the enterprise human resource managers should be based on the enterprise, using the development view of the problem, situation, constantly updated management concept, using the new management idea, continuous development and improve the talent comprehensive strength of enterprises, for the development of the enterprise develops the powers of the strong back.

Knowledge innovation and application is the soul of the enterprise. Knowledge-based enterprises may be due to its unique knowledge and maintain competitive advantage in a certain period of time, but as a result of knowledge is to learn, after a period of time will inevitably be imitated by competitors. Therefore, only to maintain the constant innovation of knowledge and use of innovation can ensure enterprise gain long-term competitive advantage and always in the industry leading level. Through professional human resources research for many years in China, we can learn that in the human resources management, incentive mechanism as the management of catalyst, in the human resources management not only start the potential employees playing an important role, has inspired employees sense of belonging and loyalty, enable employee to better service for the enterprise. Therefore, no matter in any time, any case the incentive mechanism is the key link in human resources management. By recent reform and development of incentive mechanism, it is easy to find, as market, economy, and the change of The Times, incentive mechanism is also in constant change. Is also for this reason, in view of the current increasingly complex pluralistic social environment and the demand, the enterprise should build more multi-level incentive mechanism.

For knowledge enterprises, implement the strategy of knowledge management is the enterprise survival and the development inevitably choice. Knowledge management emphasizes the knowledge, information, human resources, market and management process, coordinate, and the most effective and maximizes the enterprise the management effect. Knowledge management is the core content of knowledge sharing and new plane. Due to the basic flow of knowledge in the enterprise of happened anytime and anywhere, the knowledge production, dissemination, utilization and innovation with the whole process of enterprise activities, always so throughout the enterprise knowledge management activities at the same time, because the knowledge become the strategic resource of enterprises, so knowledge management should become the core content of enterprise strategic management which is the inevitable choice of survival and development of knowledge-based enterprises.

The Combination of Incentive Control and Management. Enterprise wants to in market competition, in addition to continuously improve enterprise's strength, also continue to deepen the reform and constantly improve the own management mechanism, to do a good job of corresponding human resource management. Specifically, the enterprise to strengthen the development and management for internal talent, according to the work need to choose the suitable staff, good for employees to give encouragement, can build up step by step with the development of social undertakings that matches the modern management mechanism, promote enterprise's development and progress. Under the background of new economy, talent has become the important driving force of the development of the enterprise, employees can use new theory, technology and professional knowledge will directly affect the enterprise's development and progress. The actual situation of the current our 
country enterprise management system, a large number of enterprise internal management mechanism is not perfect, department is more and more dispersed, between various departments work relatively independent can't work very well coordinated, cannot be well formed an organic whole.

Therefore, the enterprise of the related management personnel must attach general importance to management organization setup and coordination between departments, from the overall perspective of the knowledge of enterprise internal resources reasonable integration, the enterprise the individual organically into a whole. According to the actual situation of each enterprise innovation, to develop a more suitable for the development of the enterprise human resources management mode, innovative, targeted for human resource management, constantly improve the level of enterprise human resources management, reasonable allocation and use of talent, improve the economic efficiency and the comprehensive strength of enterprise, thus in an impregnable position in market competition.

\section{CONCLUSIONS}

In this paper, we conduct research on the new pattern and applications of incentive control mechanism on enterprise human resource management. With the speeding up of economic globalization, the new economy has gradually by people worldwide recognition, as a kind of network technology based economic model of sustainable development, talent and knowledge become the dominant. So, in today's society to talented person's demand is very urgent, enterprises to grow up in the long run it must attach importance to talent, attract more talents to join. In our current form, most of the enterprises and institutions for talent management or very seriously, some companies will also be for human resource management innovation as enterprise development work in the first place. Our research discusses the mechanism in detail which will obtain special meaning.

\section{References}

[1] Xia J, Deng H, Fang C, et al. Spillover Effects of Organizational Citizenship Behavior in Enterprise Human Resource Management-Taking Small and Medium-size Distilleries as the Examples[J]. Liquor-Making Science \& Technology, 2014.

[2] Ju, R. (2014). Innovation and transformation of state-owned enterprise human resource management under new situation. Modern Industrial Economy \& Informationization.

[3] Wang A, Jun L I. On the Risk Assessment of Human Resource Management in Petroleum Sales Enterprise Based on Risk Matrix[J]. Journal of Xian Shiyou University, 2014. 